JEFAS

26,52

\section{Editorial: \\ An upcoming 30th anniversary encouraging the papers' publication}

We are proud to present the December edition, 52nd issue, of the Journal of Economics, Finance and Administrative Science (JEFAS), offering high-quality publications in English twice a year with double-blind peer-reviews. This standard provides us to be one of the most relevant empirical research open journals in the category of economics, econometrics and finance, according to SCImago Journal Rank, from Latin America to the World. Starting next year, this journal receives the 30th anniversary of its foundation as Cuadernos de Difusión. Therefore, this Editorial wants to start the celebrations by announcing the release of our new Open Journal System with the complete archive containing published papers since Vol. 1 No. 1 (March 1992).

Moreover, seeking to increase the visibility and impact of the journal substantially, JEFAS updated its summary and indexing in multiple databases: "Acceso Libre a la Información Científica” (ALICIA by Concytec, Peru); British Library; Cabell's Directory of Publishing Opportunities; Crossref; Directory of Open Access Journals (DOAJ Seal); Directory of Open Access Scholarly Resources (ROAD); EBSCOhost; EconBiz (ZBW); EconLit; EconPapersIDEAS: Articles; Gale OneFile; "La Red Federada de Repositorios Institucionales de Publicaciones Científicas" (LA Referencia); Latindex Directory; "Matriz de Información para el Análisis de Revistas" (MIAR); "Mutualisation d'Informations sur les Revues et leurs Accès dans les Bases En Ligne" (Mir@bel); ScienceGate; "Système Universitaire de Documentation" (SUDOC); ProQuest; Scopus; Sherpa/Romeo; SciELO Citation Index (Web of Science collection); and WorldCat.

Furthermore, JEFAS reaffirms its institutional commitment to open access by being part of three major world indexes: Directory of Open Access Journals (DOAJ Seal), Directory of Open Access Scholarly Resources (ROAD) from ISSN and SciELOCitation Index from Web of Science to openly contribute on the worldwide scientific knowledge and commit for narrowing the science-practice gap in open science (Aguinis et al., 2020).

Therefore, JEFAS has internationally signed the Declaration on Research Assessment (DORA), which recognizes the need to improve how researchers and the results of academic research are evaluated.

In addition, in these months, we have renewed and extended invitations to be in the portfolio of specialized scientific journals to call, review and publish the best manuscripts accepted in international conferences of the most significant prestige from Iberoamerica:

(C) Nestor U. Salcedo. Published in Journal of Economics, Finance and Administrative Science. Published by Emerald Publishing Limited. This article is published under the Creative Commons Attribution (CC BY 4.0) licence. Anyone may reproduce, distribute, translate and create derivative works of this article (for both commercial and non-commercial purposes), subject to full attribution to the original publication and authors. The full terms of this licence maybe seen at http://creativecommons.org/licences/by/4.0/ legalcode. 
Latin American Council of Management Schools (Cladea), Business Association for Latin American Studies (BALAS), International Finance Conference (IFC).

\section{From published papers}

Since the creation of the JEFAS as Cuadernos de Difusión in 1992, subsequently ratified in 2012 with our publisher agreements and global indexes such as Scopus (Figure 1), the positioning of our journal in economic and business research from emerging and developing economies to the World has been growing throughout from all continents, achieving the highest number of publications from Latin America and Asia, followed by Africa, Europe and North America.

Likewise, as shown in Table 1, of the most representative regions, the publications of Latin America come from the countries of Colombia, Peru, Mexico, Chile, Brazil, Ecuador, Argentina, Costa Rica, Puerto Rico; while Asian publications come from the countries of India, Malaysia, Pakistan, Saudi Arabia, Turkey, Vietnam, China, Indonesia, and Iran.

Complimentarily, from a systematic literature review, in the previous Editorial (Salcedo, 2021), it was possible to verify the most relevant authors, citations, references, keywords, establishing a roadmap. Therefore, in this Editorial, an additional purpose of sharing with our readers, authors and reviewers is to understand how the journal can continue consolidating its aims, scope and guidelines to encourage successful papers' publication.

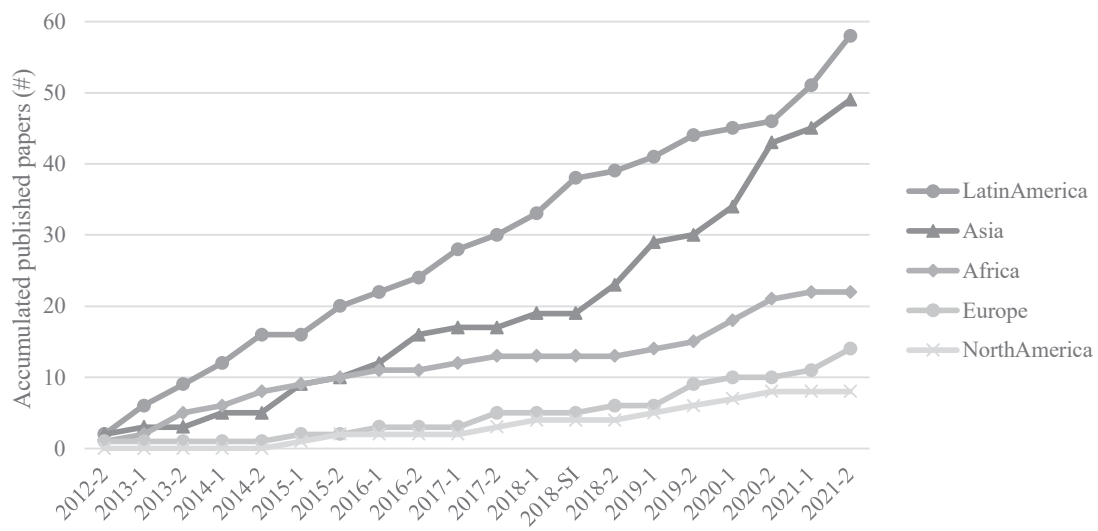

Note(s): Since 2012-2, JEFAS developed its first publisher agreement and joined Scopus

Source(s): Own elaboration based on JEFAS data

Figure 1. Accumulated published papers by the regional origin of the corresponding author

\begin{tabular}{lrlr}
\hline Latin America & $\%$ & Asia & $\%$ \\
\hline Colombia & 28.8 & India & 24.0 \\
Peru & 27.1 & Malaysia & 20.0 \\
Mexico & 13.6 & Pakistan & 14.0 \\
Chile & 8.5 & Saudi Arabia & 10.0 \\
Brazil & 8.5 & Turkey & 10.0 \\
Ecuador & 5.1 & Vietnam & 8.0 \\
Argentina & 5.1 & China & 6.0 \\
Costa Rica & 1.7 & Indonesia & 4.0 \\
Puerto Rico & 1.7 & Iran & 4.0
\end{tabular}

Source(s): Own elaboration based on JEFAS data

Table 1. Published papers by the country origin of the corresponding author (2012-2021) 
JEFAS

26,52

180

\section{From successful structure}

One of the essential points that the JEFAS has consolidated is capturing the journal's aims and scope through its published papers, leveraging the competitive advantage of scholars.

Taking the advice borrowed from Lazzarini (2012) as shown in Figure 2, one of the critical aspects to achieve a successful research structure is to consider, from a literature review with a seminal theoretical/methodological framework, the local refinements of the context to be studied. Likewise, to enrich global knowledge, moving from particular data to comparative data among countries has provided the research with a richer vision of our regions for the World.

Along this path, another critical aspect that JEFAS has considered is the manuscript structure. Manuscripts of empirical social science journals usually consist of six parts (Sun and Linton, 2014): introduction, literature review, methodology, results, discussion and conclusions.

According to this structure, first, the introduction should provide background information, by identifying the research gap and proposing the research question(s). In order to achieve this section, a regular suggestion is to follow the editor's comments from the Academy of Management Review (Barney, 2018). Second, the literature review should include background theory(s), conceptualizations, hypothesis formulation and model development. Here, a recommended consideration, as an example, is to follow the practical guide for making theory contributions in strategic management (Makadok et al., 2018). Third, the methodology should minimally focus on research design, data collection and analytical procedure, including descriptive statistics, data profile, validity and reliability. For this section, a suggestion to consider could be an evidence-based best practice study on improving methodological transparency conducted during scientific research (Aguinis et al., 2018). Fourth, the results should report the core research findings and interpretations, especially concerning hypotheses. Fifth, the discussion should compare and contrast the results to existing literature and thought. More importantly, it explores the theoretical implications (Corley and Gioia, 2011), practical - managerial/policy - implications (probably the major paper value-added) and the limitations and future research agenda. Currently, this section requires a genuine pause to reflect on the practical implications/contributions that we can make to managers, firms, institutions, society due to the COVID-19 pandemic context that we are experiencing to the future (Watson et al., 2020). Finally, the conclusions summarize the essential parts and ideas, from the research question to the hypothesis results interpretations of the manuscript.

Concerning the latter and based on the comparative study of desk-rejected vs high-impact papers (Sun and Linton, 2014), as shown in Figure 3, in addition to considering the six sections with their suggestions, we identify two peaks to achieve high-impact papers. The first significant peak is the literature review. Then, as a sustained slope and continuous enrichment, the second peak that arises from the methodology, the results, has its top in the discussions.

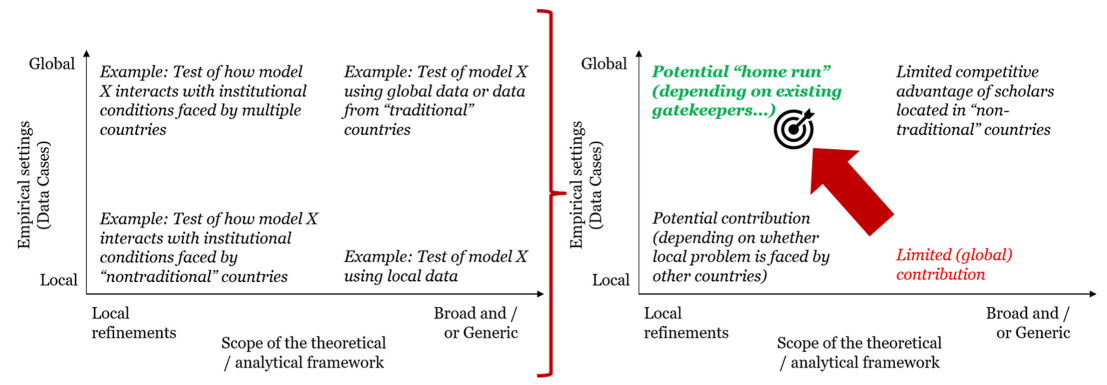

Source(s): Based on Lazzarini (2012)
Figure 2.

Leveraging the competitive advantage of emerging scholars 


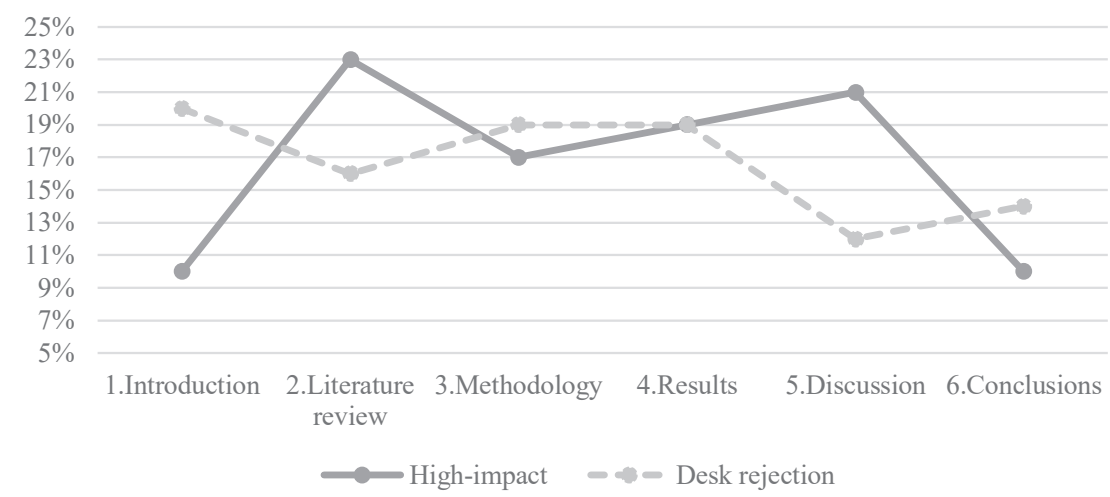

Source(s): Adapted from Sun and Linton (2014)
Editorial

181

Figure 3.

Average structure of desk-rejected vs highimpact papers

Therefore, we invite you to read this new issue, which considers a relevant part of the purpose mentioned by the Editorial. Our desire to provide high-quality manuscripts to you and society determines our goal of achieving high standards and new indexations with a committed editorial team, partners and advisors.

\section{Nestor U. Salcedo Editor-in-Chief}

\section{References}

Aguinis, H., Ramani, R.S. and Alabduljader, N. (2018), "What you see is what you get? Enhancing methodological transparency in management research", Academy of Management Annals, Vol. 12 No. 1, pp. 83-110.

Aguinis, H., Banks, G.C., Rogelberg, S.G. and Cascio, W.F. (2020), "Actionable recommendations for narrowing the science-practice gap in open science", Organizational Behavior and Human Decision Processes, Vol. 158 February, pp. 27-35.

Barney, J. (2018), "Editor's comments: positioning a theory paper for publication", Academy of Management Review, Vol. 43 No. 3, pp. 345-348.

Corley, K. and Gioia, D. (2011), "Building theory about theory building: what constitutes a theoretical contribution?", Academy of Management Review, Vol. 36 No. 1, pp. 12-32.

Lazzarini, S.G. (2012), "Leveraging the competitive advantage of Iberoamerican scholars", Management Research: Journal of the Iberoamerican Academy of Management, Vol. 10 No. 1, pp. 64-73.

Makadok, R., Burton, R. and Barney, J. (2018), "A practical guide for making theory contributions in strategic management”, Strategic Management Journal, Vol. 39 No. 6, pp. 1530-1545.

Salcedo, N.U. (2021), "Editorial", Journal of Economics, Finance and Administrative Science, Vol. 26 No. 51, pp. 2-6.

Sun, H. and Linton, J.D. (2014), "Structuring papers for success: making your paper more like a high impact publication than a desk reject", Technovation, Vol. 34 No. 10, pp. 571-573.

Watson, R., Ives, B. and Piccoli, G. (2020), "Guest editorial: practice-oriented research contributions in the COVID-19 forged new normal”, MIS Quarterly Executive, Vol. 19 No. 2, pp. v-viii. 